\title{
Emotionality and professionalism: Exploring the management of emotions by journalists reporting on genocide
}

\begin{abstract}
The dynamic nature of reporting requires journalists to interrogate their emotions as well as their sense of professionalism. This article focuses on the complex relationship between emotionality and professionalism mediated by journalists who reported on cases of genocide. This extraordinary conflict situation provides a unique lens from which to explore the personal and professional resolve of journalists. Utilising interviews with UK journalists that reported on genocides in Rwanda and Srebrenica, this article develops a framework which characterises journalistic emotional labour as distinct, multi-faceted and somewhat contradictory. While participants described reporting as a focused, professional process in which emotions were silenced, the instinctual element and residual emotional toll associated with reporting on genocide demonstrates emotionality was not entirely absent. This article therefore provides a future template from which to explore emotional labour as part of a transformative relationship between journalists' emotionality and professionalism.
\end{abstract}

Keywords: Emotion management, emotion work, emotional labour, emotions, genocide, journalism, organisational culture, Rwanda, Srebrenica.

Author: Dr Caitlin Knight - University of Roehampton, UK

Department of Social Sciences

Hirst Building, Rm 208

University of Roehampton, London, SW15 5SL

\section{Caitlin.knight@roehampton.ac.uk}




\section{Introduction}

Research on emotions, especially in the workplace, has garnered sociological interest since Hochschild (1983) discussed how employees in certain industries enhance, imitate or suppress emotions to meet job expectations. This emotion management in the workplace, or 'emotional labour' (Hochschild, 1983: 7), reveals the transmutation and commodification of emotions by organisations for profit. Hochschild's emotional labour has been critiqued, however, for assuming that emotion management is solely for the interest of the organisation (Bolton, 2005). Instead, emotional labour can been reconceptualised as a more multidimensional, dynamic and integrated process (Grandey and Gabriel, 2015) with individuals acting as 'multi-skilled emotion managers' (Bolton and Boyd, 2003: 305). While emotional labour research has recently widened in scope, journalism remains underresearched due to its objective tradition (Feinstein, 2006; Wahl-Jorgensen, 2018). Given the increase of emotion management associated with what can be considered 'therapy culture' (see Furedi, 2004), this focus on journalistic emotional labour provides a distinct case from which to interrogate the relationship between emotionality and professionalism.

This article examines journalistic emotional labour by focusing on journalists that reported during genocide. Recent research has highlighted the emotional and professional challenges faced by journalists reporting during war and conflict (see Allan and Zelizer. 2004; Tumber 2006), yet the scale of violence in genocide is an extreme and extraordinary situation to manoeuvre. The present research therefore focused on two cases of genocide: Rwanda and Srebrenica. Previous research on these two cases examined reporting without considering the experiences of the journalists, especially their emotions (e.g. Meyers et al., 1996; Wall, 1997). Recently, Wahl-Jorgensen (2018) has called upon researchers to adopt a life-history approach to historically reflect upon the experiences and lives of journalists as sociologically meaningful to the changing nature of journalism. This article answers this call 
by examining the emotional challenges journalists mediated as they reported during Rwanda and Srebrenica and in doing so, interrogates the relationship between professionalism and emotionality more broadly.

\section{Professionalism and Emotion Management in Journalism}

Emotion remains under theorised in journalism because of the tradition towards objectivity in reporting (Feinstein, 2006; Wahl-Jorgensen, 2018). Objectivity is a professional value for journalists who are expected to be fair, accurate and truthful in their reporting (Aldridge and Evetts, 2003). Santos (2009) explains that journalistic objectivity promotes impartiality through certain reporting rituals. For instance, journalists are expected to include 'both sides' in stories and avoid any conflict of interest by distancing themselves from the story and its subjects. These rituals are professionally encouraged through interactions between journalists, colleagues and editors (Deuze, 2005). Objectivity acts as a 'strategic ritual' (Tuchman, 1972: 678) which establishes journalists as detached and unbiased in their work. The objective and rational foundations of journalism may then appear contrary to emotion. However, research on emotion has increased as part of a more general 'affective turn' (Clough and Halley, 2007: 2) across disciplines, including journalism (Beckett and Deuze, 2016). In fact, Peters (2011) claims that if we consider the social component of emotion then emotion has always been part of journalism.

From a sociological perspective, the social component of emotion explores the experiences, organisation and behaviour that help construct our emotions (Turner and Stets, 2005). Emotions can be understood as micro-level instincts (Berezin, 2002). For instance, Schultz (2007: 190) describes the journalistic 'gut feeling' Danish journalists rely upon to determine newsworthiness as something very physical, 'something like a feeling' (Schultz, 2007: 199), and Jukes (2017) discusses an instinctive dimension in journalistic practice. 
Further research has also explored the use of emotionality in reporting (Pantti, 2010; WahlJorgensen, 2013) and journalists' response to traumatic events (Richards, 2007). This article seeks to further examine the complex nature of emotion within journalism reflexively through experiences during and after reporting. The distinction Hochschild (1983) makes between 'emotion work' as emotion management in private life and 'emotional labour' as specifically for a wage, does not account for the blurring that can occur between work and private life. As emotional labour becomes part of the way individuals manoeuvre through 'emotional zones' (Bolton, 2005: 64) they encounter in the workplace, it can extend into private life. Journalists are an interesting focus then to interrogate this relationship between emotionality and professionalism considering the dynamic nature of reporting.

\section{Genocide and Emotional Labour}

The objective foundation of journalism places distinct pressure on journalists to maintain a clear demarcation between work and personal lives, especially emotionally. For instance, Hopper and Huxford (2015: 32) found that journalists managed their emotions as part of 'acting professionally' and that objectivity was part of this. However, objectivity can be problematic during reporting because events must be analysed and interpreted, so objectivity may not always be possible (Richards and Rees, 2011; Skovsgaard et al., 2013). Instead, journalists may distinguish between objectivity as an ideological construct, or 'objectivity-asa-value', versus its practical translation, or 'objectivity-as-a-practice' (Carpentier and Trioen, 2010: 314). Nonetheless, even if journalists acknowledge this difficulty they still avoid including themselves in stories. Instead, they incorporate 'standard terms and depersonalised voices that camouflage the self' (Kreiger, 1991: 32) much as social scientists do. It is important then to consider how a traditional professional value, such as objectivity, might become realigned when reporting on events that challenge journalists emotionally. Research 
has reflected on the challenge of war and conflict reporting (see Allan and Zelizer, 2004; Markham, 2011; Tumber 2006), as well as crisis and trauma reporting, for journalists (see Hopper and Huxford, 2015; Jukes, 2017; Kotisova, 2017). The distinct and extreme inequity of violence defined by the label of genocide therefore produces an interesting lens through which to re-examine professionalism (Aldridge and Evetts, 2003) and emotionality in journalism.

Emotional labour can improve organisational behaviour in employees but in situations with high emotional demands, emotion management can become a difficult balancing act. Previous research has found that journalists that cover war have a higher prevalence of PostTraumatic Stress Disorder (PTSD) and depression (see Aoki et al., 2012; Feinstein et al., 2002; Pyevich et al., 2003; Simpson and Boggs, 1999). Where other jobs have built-in organisational help for these issues, journalists are more reluctant to ask for formal help due to the silencing and stigmatisation of psychological issues within their industry (Feinstein et al., 2002; Greenberg et al., 2009). The present research therefore considers the potential negative effects of journalistic emotional labour and its long-term effects as part of the emotional experience of these journalists.

\section{Rwanda and Srebrenica: Context}

This article focuses on cases of genocide that occurred in Rwanda and Srebrenica in the 1990s. The distinct geo-political context of each case is important when observing the nuances of emotional labour between journalists. In the case of Rwanda, a lack of UK media interest in news from Africa contemporaneously meant that a small number of Western journalists were present at the start of the genocide. These journalists witnessed first-hand violence and experienced the direct and continued effect of the killings as they reported and interacted with the victims (Hilsum, 2007). In the case of Srebrenica, its European location 
and the presence of British troops as part of a UN force during the Bosnian War meant it had a greater UK media presence. These journalists had been reporting in the region prior to the genocide, though once the enclave fell to the Bosnian Serb army they were barred access to Srebrenica. This meant that journalists did not witness first-hand violence but interacted with victims once they arrived in the neighbouring town of Tuzla. These victims were comprised of the women, children and elderly people that were allowed to leave Srebrenica and later, men that had been able to escape the enclave (Rohde, 2012).

These differences provide a foundation from which to consider the emotional experiences of journalists reporting from two distinct cases of genocide. It acts as a starting point from which to consider emotionality and professionalism in two extraordinary reporting situations. These differences will be considered as part of the nuanced account of emotional management which the data will reveal and therefore will be taken into account when constructing a collective narrative of emotional labour amongst these journalists.

\section{Aims and Objectives}

This study endeavours to capture the nuances present in the emotional experiences of journalists that reported on these cases of genocide. It utilises the perspective of journalists that reported on the ground to interrogate the emotionality and professionalism in reporting from first-hand accounts of this mediation. Through life history interviews the lives and experiences of these journalists therefore take precedent.

\section{Method}

\section{Participants}

Life history interviews were conducted with print journalists that reported during the 1994 genocide in Rwanda or the 1995 genocide in Srebrenica, and whose reports were published 
by UK news organisations. Although they will be referred to as 'journalists' throughout, all participants were news reporters at the time. Wahl-Jorgensen (2018) maintains that life history interviews can help conceptualise how journalists are emotionally affected by their work, the way in which they perform emotional labour and how this transforms their professional identities. The coverage of each genocide in UK newspapers was explored via a search of the database LexisNexis. Both purposive sampling and chain-referral sampling were utilised (Biernacki and Waldorf, 1981). Journalists were contacted through personal and professional websites or sometimes via a third party, such as a past work colleague. In total, 22 journalists were interviewed, 8 women and 14 men. Of these journalists 12 reported on the genocide in Rwanda and 10 on Srebrenica (see Table 1). Each participant signed a consent sheet prior to interview which assured anonymity throughout the study, so identifying details have been removed.

\section{Procedures}

Qualitative, semi-structured interviews were conducted with journalists between May 2014 and March 2015. Face-to-face interviews were prioritised and took place in London. In instances of geographical constraints, interviews were conducted via Skype or telephone. The average length of these interviews was 65 minutes. Due to the sensitive topic of the research, email interviews were also utilised where participants preferred to respond in their own time (see Table 1). Semi-structured email interviews have been found to be a viable alternative to face-to-face or telephone interviews (Meho, 2006).

The same interview schedule was used for all interviews. Questions were related to: assignment to the genocide, reporting during the genocide and the writing and editing processes which followed. Interviews were chronological as journalists spoke about what they were doing prior to the genocide, through to the experience of reporting during the 
genocide and after. Considering the interest in emotions, journalists were specifically asked about their emotional conceptualisation of events as they unfolded. Specifically, they were asked to discuss what emotions they remembered feeling and how they dealt with experiencing these events while reporting. They were also asked to discuss any experiences with victims and perpetrators. These questions provided cues for participants to elaborate their emotional experiences and avoid constraining their responses.

The use of a mixed mode interview strategy warrants consideration of limitations related to different data collection types. Since email interviews do not occur in real-time, there can be a risk of miscommunication where other interview methods rely on immediate verbal cues for clarification. To account for this, email interview questions were selfexplanatory and if responses needed further elaboration, follow-up questions were provided by the researcher (Meho, 2006). Rapport building can also prove challenging for email interviews where in other interview methods this is more immediate between researcher and participant. The sensitive nature of this study was taken into account and it was considered better for rapport building to respect the preference of participants that wanted to respond in their own time. Furthermore, the quality of material rendered via email interviews has been found to be as rich as that obtained from traditional interview methods (Meho, 2006).

Interviews were recorded and transcribed verbatim directly following the interview. Interviews were selectively coded with codes that first derived from the literature and were then revised according to the interview data, always using the constant comparative approach (Corbin and Strauss, 2007). The focus of the data was narrowed to the emotional experiences of reporting during Rwanda and Srebrenica to create an account of emotionality and professionalism for these individuals. Although interviews referenced events that took place 20 years prior, memory recall was not an issue. Journalists remembered details of their reporting and many commented on their vivid recollection of these extreme events. In 
interviews journalists were also provided with examples of their own reporting, which served as a memory prompt for questions related to writing and editing processes.

\section{Results: Manifestations of Journalistic Emotional labour}

Emotions were managed in complex and sometimes contradictory ways by participants. While these themes simplify to some extent the intricacies of journalists' experiences, they identify three key manifestations of journalistic emotional labour evident in the data.

\section{Professionalism, Process and Emotional Silencing}

The first manifestation of emotional labour reveals journalists' focus on professionalism and the process of reporting. Their concept of professionalism hinged on the ability to report since, as Martin said, 'It is called professionalism - it was our job to report and we took it very seriously'. This became the starting point for emotion management by these journalists as they reported on genocide in Rwanda and Srebrenica. They managed emotions that would have overwhelmed or undermined reporting in this effort to maintain professionalism. As a

result, their own emotions became silenced as part of this approach, both by the industry and the journalists themselves.

In each of the interviews, journalists openly spoke about how they dealt with their emotions when reporting. These discussions demonstrated the nuances in emotion management between journalists as they focused on professionalism and the process of reporting. All of the journalists acknowledged their own emotions but described different attempts to manage them. For instance, several journalists said that they detached emotionally. Sebastian reflected on his detachment while reporting on Srebrenica:

Faced with thousands of sobbing women who grieved the loss of their husbands or sons, I realised very quickly that it's just enormous, like an ocean of emotion that 
could swallow you easily, if you poured your heart out to every grieving woman. So I, and most of my colleagues, had to detach myself. The only way the job can be done. Lisa similarly spoke of detachment as she reported on Rwanda, adding, '[t]here was clearly a sort of emotional reaction, but it was a very detached one'. For Chloe, this management meant simultaneously recognising emotions and restraining them to continue reporting: Reporting requires a distancing, conveying the realities in a way that can press emotional buttons in others. Pressing those emotional buttons cannot be done without calling on one's own emotional capacity - but it is a capacity that has to be frozen in oneself while reporting.

This demonstrated a prioritisation of the professional identity of these individuals. Lisa recalled thinking at the time of reporting, 'This is what I $d o$, this is what I $a m$, this is why I am. I'm here. And that was that'. As Eva said, 'I think at the time, there was no me. There was only the journalist'. She further described:

I was in disbelief and numb. I worked like a machine. Something switched me off and I turned into a machine. I did not do this on purpose. I think, some kind of a defense mechanism kicked in. I was later told that I was talking about what I saw and heard in a steady, neutral voice, like a navigations system in the car. No emotions. No lowering or rising of voice.

Amelie echoed this description of working like a 'machine' as she explained, 'When you work in such extreme situations as a journalist, you somehow cease to be a human being with its own feelings... you almost become a machine: You have to get as much information as possible'. This 'body as machine' (Shilling, 2012: 41) metaphor demonstrates the control and discipline over the body found within waged labour. This allegiance towards professionalism and their job embodies itself in this segmentation between personal and professional identities. This indicates how professionalism is achieved in situations where it becomes 
grounded in the prescription of the role itself (Scanlon, 2011). Sebastian explained, '[I]t does de-humanize one, in the sense that the job comes first, then your personal safety, then everything else'.

These attempts at emotion management demonstrate the complex relationship between emotionality and professionalism for journalists as they focused on reporting. Professionalism and emotions became intertwined in a 'cognitive loop' (Hopper and Huxford, 2015: 34). As journalists managed their emotions in order to report, the structure of this process of reporting actually helped them maintain emotional stability, as Charles described:

[T]hose situations where you have a structure and your day has a sort of structure to it in this utter chaos and this horror of the situation ... that's very important as a way of keeping going in those situations so that you don't get kind of lost, you don't just get depressed essentially. And lose yourself.

Similarly, Jack said that reporting 'insulates you a bit from the horror of it, and the emotions'. Speaking about the unpleasant scenes he witnessed reporting on Srebrenica, Daniel rationalised, 'Your professionalism is actually a cloak and a shield and you need that. You need that professionalism because it's what enables you to do your job'.

These journalists felt that by reporting they could maintain both their professional and emotional focus, yet this process was not always so straightforward. Freelancers like Alice and Emily did not feel constrained by newspaper politics, but others acknowledged that struggles with their desk made it difficult to maintain this emotional security. For instance, Charles described how reporting in Rwanda he felt 'undermined right from the start. And I think that it set the tone for my experience as a reporter there'. Similarly, Oliver recollected that newspaper politics meant that he 'got really angry internally', which influenced his 
experience. For these journalists, the focus on reporting did not mitigate their emotions but became a source for negative emotions due to external pressures from news organisations

Although journalists discussed their emotions at the time of reporting, their focus on professionalism and process revealed the presence of what I call 'emotional silencing'. 'Emotional silencing' refers to the attitude towards emotion and professionalism promulgated by the journalism industry and mimicked by the journalists. Since emotionality remains at odds with objectivity and traditional conceptions of the journalist as a detached observer, journalists' emotions are disregarded (Wahl-Jorgensen, 2013). For instance, none of the journalists were provided emotional support at the time. Emily explained it was not until later news organisations realised ' $[\mathrm{t}]$ hat journalists needed counselling after $\ldots$ witnessing this kind of experience [genocide]. That they didn't sort of emerge from it immune or with their emotions intact'. Daniel and Frank pointed out that news organisations did not offer counselling and training until 2001, which echoes the increase in therapeutic intervention following the September 11 attacks (Furedi, 2004). In addition, journalists' own attitudes back then towards this type of support mirrored the industry attitude. Harry recalled he and others had a '[s]ort of macho attitude. You know, counselling? That's ... for wusses, you know. And that was very much the mood'. Similarly, Arthur confessed, 'If you had offered me counselling in 1995 I would probably have run a mile', and Alice admitted, 'I [didn't] really spend too long worrying about the effects on my psychology'. This coincides with previous research that found journalists did not seek formal help because of the stig ma attached to this within their industry (Greenberg et al., 2009). This demonstrates a manifestation of emotional labour which emphasises journalists' attempts to prioritise professionalism over emotionality.

\section{Reporting, Instinct and 'Journalistic Nerve'}


The second manifestation of emotional labour demonstrates how journalists relied on their instinct when they reported on Rwanda and Srebrenica. They acknowledged the difficulty that reporting during each genocide presented for traditional professional values like objectivity and balance. If we consider instinct and emotion as intertwined (Berezin, 2002) then this implies emotionality on the part of journalists in their reporting. However, journalists were quick to describe this process as focused and professional, thereby reaffirming their professional identity.

In interviews, many journalists criticised journalistic objectivity when they discussed reporting on Rwanda and Srebrenica. Chloe reasoned, '[E]ven the most seemingly neutral, objective reporting is rarely so because journalists and their editors are human beings'. Daniel further added that 'because you give a quote from one side and a quote from the other side, that somehow or other that's you being objective. You may be balancing good against evil by doing so ... [that's] just poor journalism'. For Rwanda and Srebrenica this balancing of both sides was not appropriate, as Emily explained, '[W]e had the whole thing of the war and "you have to be objective and balanced ... there's a war going on and each side is equally to blame" and it's like, well not in this case'. If both sides had been balanced this would have created, as Frank said, 'false equivalence'. Instead, journalists reported the imbalance of the situation. Martin explained he was 'brought up with the idea of balance in reporting but if one sought to balance what was taking place ... you were by default not portraying what was happening accurately'. In fact, Isaac regretted when he did once apply balance to his reporting of Srebrenica: 'So if I had a regret ... it's that I did put all sides. Because this was mass murder and everything else is insignificant'.

This imbalance coincides with research that has highlighted concern over objective news reporting that seeks to balance both sides (Donsbach and Klett, 1993; Skovsgaard et al., 2013). Journalists critically interpreted the scenes they witnessed and therefore mediated 
journalistic objectivity, similar to Carpentier and Troen's (2010) notion of objectivity-as-apractice. Specifically, they distinguished genocide as an extreme situation and the inequity of violence meant they responded differently. As Emily said, '[S]ometimes I think your own judgments should take precedence ... we have these rules and for very good reason, to kind of make sure you don't report inaccurately, but maybe sometimes ... you should respond to situations that are so unusual'. As Isaac explained:

[I]n these extreme conditions of extreme crimes, then I think yeah these sort of traditional values ... go out the window because it's a human reaction to things like that. And we're not expected to be dispassionate when faced with such outrageous acts against humanity.

Martin explained further, "This was done "instinctively", I believe. No one sat down and said “OK let's report this differently". It just happened'. Amelie specifically described this feeling as her 'journalistic nerve', while Lisa referred to her 'gut' feeling. Previously, the journalistic 'gut feeling' has referred to journalists' instinct towards determining newsworthiness (Schultz, 2007: 190). However, journalists in the present research acknowledged that they relied upon this instinct specifically given the distinct reporting situation they were in. As Charles said, '[Y]ou can't learn how to be a foreign correspondent in those places you have to just do it and hope for the best. And rely on your instincts to sort of see you through'. This coincides with journalists from Jukes' (2017: 4) study who found during trauma reporting that they struggled with a 'visceral, empathic often instinctive affective dimension of practice' alongside embedded notions of professionalism.

If instinct and emotion are intertwined (Berezin, 2002) this reliance on instinct arguably introduces an element of emotionality into this reporting. However, as with the previous manifestation of emotional labour, journalists consistently reverted back to notions 
of professionalism in spaces where emotionality may tread too far and threaten their professional identity. For instance, Ethan added:

I'm full of impulses and opinions and prejudices the same as anyone else. But do I try and keep common sense around all of that? Yes I do. Does that preclude me from making judgment or covering stories? No it doesn't. And nor should it.

Where emotionality was acknowledged, it was done within the confines of professionalism. As Jack said, '[I]t's a professional process ... You're not really thinking about your own emotions, in terms of "wow, what am I feeling, in myself?" It's like, how can I use this to, as an experience, how can I convey it?' Harry explained that reporting on Rwanda he tried to 'give the reader a sense of what it feels like to be there. But it's not about me ... What you're feeling isn't as important as what the people around you are feeling because you're not part of it'. Wahl-Jorgensen (2013) found in award-winning journalism that journalists did not discuss their own emotions and the use of emotion was heavily policed alongside traditional parameters of objectivity. In fact, journalists in the present research considered it selfindulgent to have focused on their own emotional experiences. Ethan explained this would have belittled the victims' experiences:

I'm not going to try and pretend that I could reach to the emotional plight of what they suffered, I never suffered something like that myself, so I didn't feel I had to patronise them by saying I shared their pain when I clearly didn't. It didn't mean I didn't understand it or that I couldn't do a good job as a journalist... I remember being moved by these two little kids and their plight. I'm very defensive about trying to say that the pain of the people in Srebrenica was in any way my pain because it absolutely fucking wasn't! It just wasn't ... It wasn't the case then and it isn't now.

To admit that their own emotions were utilised in any form would threaten the professional identity that was jointly constructed by the industry and themselves; a professional identity 
that seeks objectivity over emotionality. This 'journalistic nerve' therefore became characterised in interviews as a focused and professional process. By characterising any emotionality in their reporting as only that of the victims, they maintained their emotional distance and thus their professionalism. They may acknowledge emotion, but swiftly reaffirm their professional identity. This demonstrates another manifestation of emotional labour which highlights the complex manoeuvring between emotionality and professionalism for these journalists.

\section{The Emotional Toll}

Previous manifestations of emotional labour have demonstrated how journalists negotiated their emotions while reporting. This third manifestation reveals how emotion management was not all-encompassing and meant that journalists experienced negative long-term emotional effects as a result. This extends previous research on depression and PTSD among journalists (Aoki et al., 2012; Feinstein, 2006; Pyevich et al., 2003). While journalists reported a range of symptoms, interviews collectively revealed the emotional toll experienced as a result of reporting during Rwanda and Srebrenica.

In interviews, journalists explained how difficult it was to deal with their own emotions when they were expected to be professional and continue reporting. Emily explained, '[W]e all ... at times allowed our emotion - or didn't allow it - [but $]$ our emotions overwhelmed us and we found it extremely difficult to function properly and do our reporting properly'. James admitted he was 'attached emotionally' to the region when he reported on Rwanda, as were Sebastian and Amelie when they reported on Srebrenica. Anna described how her personal interactions with victims made it difficult for her to report: 'Emotionally, it was rather different for me because I had friends that were being murdered ... I was not going into a story, I was in there, in that sense I was living the story'. This demonstrates the 
balancing act of managing emotions for these journalists considering the scenes they witnessed and the attachment they felt. Martin specifically recalled, 'I remember disgust at what had happened, fear that here in this place where life meant nothing my own life could be taken at any moment and so I missed my children and family'.

When discussing long-term effects of reporting on Rwanda and Srebrenica, several journalists spoke specifically about PTSD. Danielle spoke openly about her PTSD diagnosis after reporting and Jack recalled, 'I know I was suffering some degree of PTSD. I was extremely agitated, so I couldn't sleep. I was having nightmares. I was just in, a sort of, bad mental state and distressed, in some way'. Others, such as Lisa, did not use these terms but described symptoms:

I never had any nightmares, never had anything like that. And I didn't cry. What I did do is I felt I was in a movie. I felt I was looking through a video camera. ... for about six months afterwards my only symptoms [were] that the sky didn't look so blue and the grass didn't look so green. It was like the colour, the world had been colourwashed.

This coincides with previous research that found high incidences of PTSD and depression among journalists (Aoki et al., 2012; Feinstein et al., 2002; Greenberg et al., 2009). Several journalists did not specifically refer to PTSD but spoke of 'trauma'. Isaac said, 'I think the most traumatising is that you feel the grief, the very live and immediate and raw grief'. Oliver remembered when he returned from Rwanda that he was 'absolutely exhausted and utterly miserable'. While this occurred across both genocides, witnessing killing first-hand affected journalists that reported on Rwanda and some journalists did not return for further reporting as a result. Harry remembered thinking, 'I'm gonna see terrible things ... and I must admit I didn't feel like going back and that's why [his colleague] went down and took over'. Similarly, Jack recalled he was 'having difficulty dealing with it because it was quite horrific, 
what we all witnessed in there ... I didn't feel mentally able to face up to it. I just didn't want to do it [reporting on the genocide] again'. Even journalists that did not acknowledge PTSD or speak directly about 'trauma' still described negative and depressive symptoms related to stress. For instance, William said, 'I don't have nightmares about any of the stories I wrote. My nightmares are all about communications going down and not being filed and the story not read and that was the stress'. These discussions collectively demonstrate the emotional toll of reporting.

Journalists were also heavily critical towards their reporting of these events and spoke about the guilt and regret they harboured. Isaac theorised, 'There is a burden of guilt there, in the act of journalism and in war zones in particular, that contribute[s] to that sense of posttrauma'. For instance, James spoke openly about failure in respect to Rwanda:

Yet given all of this, what we know is what we all failed dreadfully in Rwanda. My inability to perceive the enormity of it, to be able to express it properly in words which was the only thing I could do because it was my job, this failing is what I and others of my trade will carry to the grave with sadness... All of us would I think agree that we could have done a better job before, during and after the events of 1994 . Daniel echoed this sense of guilt and inadequacy in respect to Srebrenica: 'I didn't feel I played a particularly worthwhile or effective role as a journalist. I didn't feel my journalism was good at the time. So there's a sense of guilt and a sense of inadequacy there'. Other journalists spoke about guilt related to 'war profiteering'. Frank explained, '[T]here's an element of journalism where you're a vulture, you're profiting off of the misery of others'. The regret and guilt they harbour in relation to reporting on Rwanda and Srebrenica again reveals the emotionality of a job that consumes them both in the field and outside it. Interestingly, Danielle associated her feelings of guilt to her work now with Syrian refugees as she explained that she "found very difficult as a journalist that you go along and say, "tell 
me all about what you're going through" and then you leave. Whereas now I hang around and try to help make their lives less miserable'.

The emotional toll these journalists experienced reveals the extent to which this reporting enveloped their lives regardless of attempts at emotion management. They recalled how this stayed with them and shaped their life as a result. Daniel acknowledged, '[T]he whole Bosnian War and that Srebrenica experience kind of made me who I am intellectually and morally', while Danielle reflected upon marrying someone who also spent time in Bosnia. Eva recalled, 'For 20 years I am writing about Srebrenica'. She added that Srebrenica 'put many events in my own life in perspective. I was never upset about my child's bad grades, about trains that run late, about editors shortening my stories, about divorce ... none of this matter[s]'. As James explained, 'I don't think one recovers from Rwanda. It would be rather obscene to get over something like that. What I know is that among my colleagues ... they carried on working hard on fresh stories. Some died. Some are alive'.

However, even where journalists acknowledged the cumulative effect this reporting had on them, it was framed in a way that detracted from the emotion they experienced. For instance, Luke rationalised the nightmares he experienced after Rwanda:

In the end [I had] nightmares about being chased through banana groves carrying my children in my armpit or finding myself dressed in a military uniform I don't recognise or want to be in, with a bent gun. Standard. If you'd been in a car crash you'd have nightmares about it.

James similarly justified the effect that Rwanda had on him:

Scar tissue builds up so much that to an extent one doesn't recall what there was beneath it once. But you don't need a Rwanda to be scarred: the most mundane lives produce great pain and in a way at least I have an excuse.

The journalism industry expects journalists to place their job ahead of themselves (Feinstein, 
2006) and journalists demonstrate their reinforcement of this pressure. They accept an unwritten code to report on events regardless of the situation or risk of harm to themselves (Simpson and Boggs, 1999). This normalisation reveals their conformity to the professional expectations of their job role. Individuals were presented with a situation where they had to actively perform emotional labour to avoid the emotionality implicit in reporting genocide. The constant emphasis placed on professionalism reflects the organisational expectations and pressures of journalism which account for the emotional silencing they sustained. Luke echoed this emotional silencing:

[O]f course there was an emotional toll. As there should be. Sort of whining on about the emotional damage ... PTSD is an extremely unpleasant injury but it's very easily fixed, pretty much, if rapidly identified. Not that it was either fixed or identified in me, but I'd rather get PTSD than lose a hand. And boo hoo, you covered a fucking genocide, what do you expect?

Research has shown that the stigma around PTSD in journalism makes journalists reluctant to ask for help (Greenberg et al., 2009) so it is not surprising that they take it upon themselves to deal with the after-effects. Emily rationalised, '[I]t would've been good if we just soldiered on and in a way, been less emotionally upset by it. And just kept reporting, whatever our feelings are, you know, it's our job'. The description of long-term emotional effects that these journalists have experienced reveals the importance of exploring journalistic emotional labour during extraordinary events.

\section{Discussion}

The framework set forth in this article reveals journalistic emotional labour as a dynamic, multidimensional process where each manifestation overlaps, loops and feeds back. This furthers Grandey and Gabriel's (2015) conceptualisation of emotional labour as an integrated 
process which is better understood by the sum of its parts. Together each manifestation highlights the contradictions that exist between the organisational expectations placed upon journalists and what is experienced in the field. Journalists discussed how they managed their emotions in an effort to maintain their professionalism, which reveals the pressures of an industry that emotionally silenced them and enabled them to emotionally silence themselves. Yet interviews revealed circumstances where the emotional investment that reporting during such extraordinary events elicited was not entirely absent. Journalists acknowledged that they relied on their instinct for this reporting which revealed trust towards their own feelings and judgments. Nonetheless, they constructed this as a focused, professional process devoid of emotion that might threaten their professionalism. The investigation of emotionality within journalism is therefore very complex and steeped in professional traditions and expectations (Hopper and Huxford, 2015; Richards and Rees, 2011; Wahl-Jorgensen 2018; 2019).

The emotional toll that journalists experienced as a result of reporting during Rwanda and Srebrenica demonstrates the struggle of mediating emotionality and professionalism in this job. While journalists acknowledged that negative emotional effects transcended into their personal lives, they also normalised these experiences and effects as 'part of the job'. Furedi (2004) argues that British society has adopted what he calls a therapy culture, where institutions increasingly co-opt the language of therapy. Therapeutic terminology, such as PTSD, that was once used for those who experienced extreme and extraordinary events is now largely used to acknowledge human vulnerability. Yet in the case of journalism, the inverse has occurred: reticence of both news organisations and journalists to engage with this type of language after reporting on genocide. This presents an opportunity to interrogate emotionality more broadly and the sociological effects that this emotion language can have on individuals working not just within journalism, but other industries — and suggests that notions of professionalism may be an important counter on the adoption of the language of 
therapy in certain contexts.

The inherent emotionality associated with reporting in extraordinary situations encourages us to interrogate the concept of professionalism within this industry. The relationship between professionalism and emotionality therefore should not be mutually exclusive, but cooperative. Journalists' emotionality was not completely silenced in the process of their reporting, which raises the question as to whether it should be. As Anna admitted, '[I]f you have no empathy for the victims in a situation like that, then you shouldn't be a journalist. You should be an accountant'. This extends Aldridge and Evetts' (2003) call for a reinterpretation of the concept of professionalism in light of this relationship and in consideration of journalism's 'affective' future (Beckett and Deuze, 2016). Journalists garner a feel for reporting based on their experiences within a variety of different reporting situations, each of which may call upon different parts of the professional arsenal they have developed. Contrary to journalistic tradition, emotionality may not be an adversary to professionalism, but a support. With journalistic emotional labour it is possible then to expand Bolton's (2005) conceptualisation of the complexity and richness of workplace emotion.

This article focuses on journalists that reported during two cases of genocide in order to interrogate the relationship between professionalism and emotionality for these individuals during an extraordinary reporting situation. Each of these cases provides a distinct geopolitical context from which to consider the emotional labour performed by journalists. For instance, the first-hand violence that journalists specifically witnessed in Rwanda became a crucial part of the emotional toll they experienced; journalists reporting on Srebrenica also discussed trauma symptoms as a result of their experiences with victims even though they did not directly witness the violence. In both cases, journalists verbalised guilt and regret towards their reporting. Thus, while different geo-political contexts will influence experiences of 
reporting in diverse ways, commonalities in emotional labour and traumatic experiences point to broader troubling effects that need to be considered when reporting on genocide. This work adds then to previous research on social imaginaries and the visibility of human suffering through its discussion of journalists' emotion and attachment when reporting on genocide (Wilkinson, 2013).

Future research could apply the framework of journalistic emotional labour presented here to other reporting situations, or to other types of journalists, since emotion and attachment can occur in any reporting scenario. Further exploration and interrogation of the relationship between emotionality and professionalism in journalism is also beneficial since news has become increasingly emotionally networked (Beckett and Deuze, 2016). For instance, Rosen (2018: 1) argues that journalists reporting on President Trump should 'actively suspend normal relations'. In doing so he charges them with the duty to mediate their professionalism, and respectively their emotionality towards this post-truth era of news reporting.

Journalism studies typically focus on the industry instead of the journalists themselves and overlook the life-history approach utilised by sociological studies. By using interviews with journalists to explore notions of emotionality and professionalism, this sociological research answers Wahl-Jorgensen's (2018) call for a historical reflection of the lives of journalists. Journalists' concept of professionalism has been, and continues to evolve, amidst a broad spectrum of events. It is only by engaging with these experiences that we can establish the sociological relevance of this change for journalists within an industry that tends to marginalise emotion. The words of the journalists in this article have made it possible to recognise the emotionality inherent in reporting during Rwanda and Srebrenica, and how professional and personal identities were transformed as a result. This article acts as a narrative for journalists who were emotionally silenced, both by their industry and by 
themselves. It emphasises the importance of future emotional labour research which challenges the traditional demarcation between emotionality and professionalism within journalism.

\section{Acknowledgments}

Special thanks are directed towards Professor Mark McCormack, from the University of Roehampton, in his role as a research mentor which meant his assistance in editing and proofreading this manuscript. Many thanks are directed to the Sociology Department at the University of Surrey where the doctoral research was undertaken which this article stems from. Thanks specifically go to Dr Paul Hodkinson and Dr Mike McGuire for their guidance and supervision over the doctoral research project, as well as to Professor Marie Breen-Smyth and Dr Nicola Green for their help during the inception of it. 


\section{References}

Aldridge M, Evetts J (2003) Rethinking the concept of professionalism: The case of journalism. British Journal of Sociology 54(4): 547-564.

Allan S, Zelizer B (eds) (2004) Reporting War. London: Routledge.

Aoki Y, Malcolm E, Yamaguchi S, Thornicroft G, and Henderson C (2012) Mental illness among journalists: A systematic review. International Journal of Social Psychiatry 59(4): 377-390.

Beckett C, Deuze M (2016) On the role of emotion in the future of journalism. Social Media \& Society 2(3): 1-6.

Berezin, M (2002) Secure states: Towards a political sociology of emotion. The Sociological Review 50(2): 33-52.

Biernacki P, Waldorf D (1981) Snowball sampling: Problems and techniques of chain referral sampling. Sociological Methods \& Research 10(2): 141-163.

Bolton SC (2005) Emotion Management in the Workplace. London: Palgrave

Bolton SC, Boyd C (2003) Trolley dolly or skilled emotion manager? Moving on from Hochschild's Managed Heart. Work, Employment and Society 17(2): 289- 308.

Carpentier N, Trioen M (2010) The particularity of objectivity. Journalism 11(3): 311-328.

Clough PT, Halley J (eds) (2007) The Affective Turn. Durham, NC: Duke University Press.

Corbin J, Strauss A (2007) Basics of Qualitative Research. London: SAGE.

Deuze M (2005) What is journalism? Professional identity and ideology of journalists reconsidered. Journalism 6(4): 442-464.

Donsbach W, Klett B. (1993) Subjective objectivity: How journalists in four countries define a key term of their profession. International Communication Gazette 51(1): 53-83.

Feinstein A (2006) Journalists Under Fire. Baltimore, MD: Johns Hopkins University Press. 
Feinstein A, Owen J, and Blair N (2002) A hazardous profession: War, journalists and psychopathology. American Journal of Psychiatry 159(9): 1570-1575.

Furedi F (2004) Therapy Culture. London: Routledge.

Grandey AA, Gabriel AS (2015) Emotional labor at a crossroads. Annual Review of Organizational Psychology and Organizational Behaviour 2: 323-349.

Greenberg N, Gould M, Langston V, and Brayne M (2009) Journalists' and media professionals' attitudes to PTSD and help-seeking: A descriptive study. Journal of Mental Health 18(6): 543-548.

Hilsum L (2007) Reporting the genocide. In: Thompson, A (ed) The Media and the Rwanda Genocide. London: Pluto Press, 261-273.

Hochschild AR (1983) The Managed Heart. Berkeley, CA: University of California Press. Hopper M, Huxford JE (2015) Gathering emotion: Examining newspaper journalists' engagement in emotional labour. Journal of Media Practice 16(1): 25-41.

Jukes S (2017) Affective journalism - uncovering the affective dimension of practice in the coverage of traumatic news. $\mathrm{PhD}$ Thesis, Goldsmiths University, London.

Kotisova J (2017) When the crisis comes home: Emotions, professionalism, and reporting on 22 March in Belgian journalists' narratives. Journalism 00: 1-17.

Kreiger S (1991) Social Science and the Self. New Brunswick, NJ: Rutgers University Press. Markham T (2011) The Politics of War Reporting. Manchester: Manchester University Press. Meho LI (2006) E-mail interviewing in qualitative research. Journal of the American Society for Information Science and Technology 57(10): 1284-1295.

Meyers G, Klak T, and Koehl T (1996) The inscription of difference: News coverage of the conflicts in Rwanda and Bosnia. Political Geography 15(1): 21-46.

Pantti M (2010) The value of emotion: An examination of television journalists' notions on emotionality. European Journal of Communication 25(2): 168-181. 
Peters C (2011) Emotion aside or emotional side? Crafting an 'experience of involvement' in the news. Journalism 12(3): 297-316.

Pyevich CM, Newman E, and Daleiden E (2003) The relationship among cognitive schemas, job-related traumatic exposure, and posttraumatic stress disorder in journalists. Journal of Traumatic Stress 16(4): 325-328.

Richards B, Rees G (2011) The management of emotion in British journalism. Media, Culture and Society 33(6): 851-867.

Richards B (2007) Emotional Governance. Basingstoke: Palgrave Macmillan.

Rohde D (2012) Endgame: The Betrayal and Fall of Srebrenica. London: Penguin Books.

Rosen J (2018) It's time for the press to suspend normal relations with the Trump presidency. Available at: http://pressthink.org.

Santos J (2009) Daring to Feel. Plymouth: Lexington Books.

Scanlon L (ed) (2011) 'Becoming' a Professional. London: Springer.

Schultz I (2007) The journalistic gut feeling. Journalism Practice 1(2): 190-207.

Shilling, C (2012) The Body and Social Theory. London: SAGE.

Simpson R, Boggs J (1999) An exploratory study of traumatic stress among newspaper journalists. Journalism and Communication Monographs 1(1): 1-26.

Skovsgaard M, Albæk E, Bro P, and De Vreese C (2013) A reality check: How journalists' role perceptions impact their implementation of the objectivity norm. Journalism 14(1): $22-42$.

Tuchman G (1972) Objectivity as strategic ritual: an examination of newsmen's notion of objectivity. American Journal of Sociology 77(4): 660-679.

Tumber H (2006) The fear of living dangerously: Journalists who report on conflict. International Relations 20(4): 439-451. 
Turner JH, Stets JE (2005) The Sociology of Emotions. Cambridge: Cambridge University Press.

Wahl-Jorgensen K (2013) The strategic ritual of emotionality: A case study of Pulitzer Prizewinning articles. Journalism 14(1): 305-320.

Wahl-Jorgensen K (2018) Challenging presentism in journalism studies: An emotional life history approach to understanding the lived experience of journalists. Journalism 1-9.

Wahl-Jorgensen K (2019) Emotions, Media and Politics. Cambridge: Polity Press

Wall MA (1997) A 'pernicious new strain of the old Nazivirus' and an orgy of tribal slaughter': A comparison of US news magazine coverage of the crises in Bosnia and Rwanda. International Communication Gazette 59(6): 129-145.

Wilkinson I (2013) The provocation of the humanitarian social imaginary. Visual Communication 12(3): 261-276.

\section{Author biography}

Caitlin Knight is a lecturer at the University of Roehampton in the Department of Social Sciences. Caitlin holds a PhD in Sociology from the University of Surrey. Her research focus is the complex emotion management journalists that report from conflict situations engage in, specifically genocide, and how this relates to wider professional and organisational expectations. 
Table 1: Participant characteristics

\begin{tabular}{|c|c|c|c|c|}
\hline $\begin{array}{l}\text { Journalist } \\
\text { (pseudonym) }\end{array}$ & Gender & Case study & $\begin{array}{l}\text { Affiliation during } \\
\text { reporting }\end{array}$ & Interview type \\
\hline Alice & Female & Rwanda & Freelance & Face-to-face \\
\hline Amelie & Female & Srebrenica & Staff & Email \\
\hline Anna & Female & Rwanda & Freelance & Face-to-face \\
\hline Arthur & Male & Srebrenica & Staff & Face-to-face \\
\hline Charles & Male & Rwanda & Staff & Face-to-face \\
\hline Chloe & Female & Srebrenica & Staff & Email \\
\hline Daniel & Male & Srebrenica & Staff & Face-to-face \\
\hline Danielle & Female & Srebrenica & Staff & Face-to-face \\
\hline Emily & Female & Rwanda & Freelance & Skype \\
\hline Ethan & Male & Srebrenica & Staff & Skype \\
\hline Eva & Female & Srebrenica & Staff & Email \\
\hline Frank & Male & Srebrenica & Staff & Telephone \\
\hline Harry & Male & Rwanda & Staff & Face-to-face \\
\hline Isaac & Male & Srebrenica & Staff & Face-to-face \\
\hline Jack & Male & Rwanda & Freelance & Face-to-face \\
\hline James & Male & Rwanda & Staff & Email \\
\hline Lisa & Female & Rwanda & Staff & Telephone \\
\hline Luke & Male & Rwanda & Staff & Face-to-face \\
\hline Martin & Male & Rwanda & Staff & Email \\
\hline Oliver & Male & Rwanda & Staff & Telephone \\
\hline Sebastian & Male & Srebrenica & Staff & Email \\
\hline William & Male & Rwanda & Staff & Face-to-face \\
\hline
\end{tabular}

